the same rice yield as growing rice alone, but uses $68 \%$ less pesticide and $24 \%$ less chemical fertilizer.

The researchers surveyed farmers' fields from 2005 to 2010 and conducted field experiments. They found that fish swimming among the rice plants bumped into the stems, knocking off as many as one-quarter of pests called rice planthoppers. Nitrogen from unconsumed fish feed was taken up by the rice plants, boosting yields.

The authors say that some practices from traditional agriculture could improve the efficiency of modern farming.

Proc. Natl Acad. Sci. USA

http://dx.doi.org/10.1073/

pnas.1111043108 (2011)

\section{Towers grow by drips and drops}

Reminiscent of children building castles at the beach by dripping wet sand from their fist, researchers in Massachusetts have created their own slender towers by dripping a suspension of glass beads in a water-glycerine mixture over a granular surface.

Julien Chopin and Arshad Kudrolli at Clark University in Worcester used a highspeed camera to reveal the mechanics of the surprisingly cohesive structures (pictured). They found that they could control the shape and height of the tower by adjusting the speed of the dripping and the volume fraction of the beads in
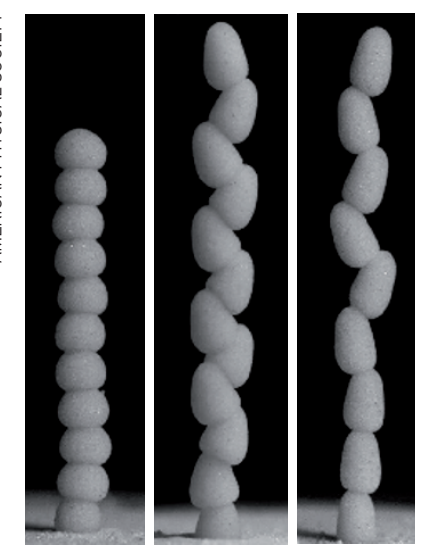

the suspension.

The researchers suggest that the technique could be an alternative route to surface patterning and threedimensional printing.

Phys. Rev. Lett. 107, 208304

(2011)

PALAEONTOLOGY

\section{Moth fossils show their colours}

Fossils of 47-million-year-old moths reveal that the insects once had a yellow-green sheen that both warned predators of their toxicity when they were exposed and provided camouflage when they were resting among leaves.

Some moths and other creatures, such as birds, derive colour not from degradable pigments, but from tiny structural patterns in feathers or scales that scatter light to produce different hues.

These structures

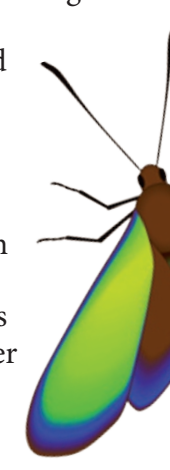
can be preserved in fossils. Maria McNamara at Yale University in New Haven, Connecticut, and her colleagues analysed fossils of moths from Germany and reconstructed the insects' original colour using electron microscopy and mathematical calculations.

The authors suggest that the moths' forewings were mostly bright yellow-green, with a fringe of blue and brown (pictured).

PLoS Biol. 9, e1001200 (2011)

For a longer story on this research, see go.nature.com/ s5gbmt

\section{APPLIED PHYSICS}

\section{Bubble-powered beads}

Tiny objects can be propelled in a controlled fashion when placed in an electric field.

Gabriel Loget and

Alexander Kuhn at the

University of Bordeaux in

COMMUNITY CHOICE

The most viewed papers in science

\title{
Stress speeds up brain degeneration
}

\section{HIGHLY READ \\ on www.jneurosci. org in October} proteins in the brain.

Prolonged stress may accelerate neurodegeneration in Alzheimer's disease by exacerbating the build-up of damaging

John Trojanowski at the University of Pennsylvania in Philadelphia and his colleagues studied mice that had been engineered to accumulate the proteins $\beta$-amyloid or tau in their brains, in a similar manner to that seen in people with Alzheimer's disease. They induced stress in these animals by housing them in isolation and periodically restraining them inside a tube. The stressed mice developed even greater amounts of brain $\beta$-amyloid or tau than non-stressed mice; they also had poorer memory and lost more brain tissue.

The researchers next treated the mice with a molecule that blocks a brain protein called corticotropin-releasing factor, which regulates the stress response. Stress no longer intensified disease symptoms in these mice, suggesting that blocking this pathway may impede neurodegeneration in people with Alzheimer's, say the authors.
J. Neurosci. 31, 14436-14449 (2011)

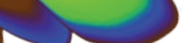

France tested metallic,

conducting beads - with diameters ranging from a few hundred micrometres to 1 millimetre - that become positively charged on one side and negatively charged on the other in an electric field. This drives oxidation and reduction reactions at opposite sides of the beads when they are in solution. The reactions produce different quantities of gas bubbles at the surface of each side, driving the beads in one direction.

The authors used their system to induce a crossshaped object more than a centimetre wide to spin. Nature Commun. http://dx.doi. org/10.1038/ncomms1550 (2011)

\section{CANCER BIOLOGY \\ Lifting the brakes on cancer}

Many cancers are thought to be driven by cancer stem cells - cancer cells that divide continuously and seed tumours. Researchers in Italy have elucidated a molecular mechanism by which one component of a key pathway linked to organ size confers cancer stem-cell properties on breast-cancer cells.

Michelangelo Cordenonsi and Stefano Piccolo at the University of Padua and their team examined the Hippo pathway, which controls organ size by inhibiting cell growth and promoting cell death. They found that levels and activity of a protein called TAZ - which inhibits the Hippo pathway - are elevated in aggressive breast tumours. TAZ is also required in breastcancer stem cells to maintain their ability to self-renew and generate tumours, and it reprograms non-stem-cell tumour cells into stem-celllike cancer cells.

Furthermore, TAZ is activated when a key regulator of the cell's spatial organization is lost.

Cell 147, 759-772 (2011)

\section{$\rightarrow$ NATURE.COM}

For the latest research published by Naturevisit:

www.nature.com/latestresearch 